\title{
Antihyperglycemic Activity of The Ethanolic Extract of the Bark of Mitragyna Ciliata (MYCA) in Albino Induced Diabetic Rats
}

\author{
PAYE Plenseh Diana'; James McClain²
}

'Instructor, School of Pharmacy, College of Science and Technology, University of Liberia, Liberia

${ }^{2}$ Assistant Professor, Department of Chemistry, College of Science and Technology, University of Liberia, Liberia

\section{Article Info \\ Volume 8, Issue 3 \\ Page Number : 957-965}

\section{Publication Issue}

May-June-2021

\section{Article History}

Accepted : 18 June 2021

Published : 25 June 2021

\section{ABSTRACT}

Background: Diabetes an epidemic that gives rise to an increased macro vascular complication mortality rate of 1.5 million annually, increasing by 2035. Treatment of diabetes is complicated and associated with a severe side effect.

Objective: To evaluate the antihyperglycemic property of the ethanolic extract of the back of MYCA and its toxicological effect on the hematological parameters with histopathological analysis of selected organs of induced diabetic albino rats.

Method: The ethanoic extract (1000 mg/kg bw and $500 \mathrm{mg} / \mathrm{kg}$ bw) and glibenclamide $(0.5 \mathrm{mg} / \mathrm{kg}$ bw) were administered to diabetic induced rats. The effect of the extract on the hematological was studied in the diabetic induced rats. Histopathological changes were observed in the liver of induced diabetic rats after the administration of the MYCA extract.

Results: The anti-hyperglycaemic effect was observed at two different levels, for two different doses $(1000 \mathrm{mg} / \mathrm{kg}$ and $500 \mathrm{mg} / \mathrm{kg})$. The results also showed significant suppression of blood glucose level in glucose fed hyperglycaemic albino rats but showed no significantly suppressed glucose level in overnight fasted normoglycemic rats.

Conclusion: The findings revealed that the ethanolic extract of MITRAGYNA CILIATA (MYCA) possess antihyperglycemic property. Besides, the extract can prevent the various complication of diabetes and improve some hematological parameters.

Keywords : hyperglycaemic, Liberia, ANTIHYPERGLYCEMIC ACTIVITY, MITRAGYNA CILIATA, ethanoic extract

\section{INTRODUCTION}

Diabetes or diabetes mellitus (type II diabetes) is on the verge of an epidemic and a significant public health issue. Diabetes mellitus is a severe global health burden. The magnitude of the mortality of this illness is alarming. Diabetes is a condition primarily defined by the level of hyperglycemia, giving rise to a risk of micro vascular damage and associated to increased risk of macrovascular complications and 
diminished quality of life. The latest surveys showed by the World Health Organization (WHO) in 2014, about 422 million adults are living with diabetes, with 1.5 million deaths. According to the International Diabetes Federation 2013 update, 8.3\% of adults, 382 million people had diabetes worldwide; by 2035, this number will rise to 592 million. Diabetes mellitus has previously been shown to be modulated by plants extracts in developing nations. [1-8].

For a long time, diabetes has been treated with several medications and several medicinal plants or their extract based on folklore medicine in low-middleincome countries. The management of diabetes with the synthetic drug without toxicological effect stay poses a challenge to researchers. In developing nations the use of plant in the treatment of diabetes because of the high cost.

The MYCA (Family: Rubiaceae) found Sub Saharan Africa and found in the tropical rain forest of Nigeria and swamp in Liberia has been identified by herbalist in the treatment of diabetes, general weakness, hypertension, dysentery gonorrhea, amenorrhea, leprosy, colds, chest pains, food poisoning and sterility $[9,10]$. Studies have also shown that the MYCA bark contains tannins, saponins, alkaloids, amino acids, steroids, terpenoids, and phenolics. These properties were found to be effective antihyperglycemic agents. However, claims of its safe usage in folk medicine are unsubstantiated by scientific studies [11-14] in developing nations.

Nowadays, the pharmacological constituents of plant extract have increased usage for medication for various illnesses and human benefits. In some countries in Sub-Saharan Africa, plant extract has been used to improve other diseases, including diabetes mellitus. The WHO estimated that $80 \%$ of the population of developing nations relies on traditional medicines, mostly plant drugs, for their primary health care needs [15-17].
Therefore, the objective of this study is to evaluate the antihyperglycemic property of aqueous extract of the bark of MYCA in the treatment of Albino induced diabetes mellitus rats. The scope of the study could lead to the discovery of bioactive constituents of MYCA that may be useful in the production of a new drug for the treatment or management of diabetes.

\section{METHODS AND MATERIAL}

\subsection{Preparation of Plant Material.}

\section{Plant Extract.}

The bark of Mitragyna ciliata (MYCA) was harvested in Jos, Plateau State, with a traditional herbalist in August 2015, authenticated. A voucher specimen was deposited at the herbarium of the Department of Pharmacognosy, University of Jos. The active principle found in the plant[18], but the research interest was the bark of the plant. The bark of the plant was air-dried and crushed into powdered. 1.5 grams of the powder was extracted with aqueous ethanol $(80 \% \mathrm{EtOH})$ by cold percolation. The extract was concentrated in a rotatory evaporator at $60^{\circ} \mathrm{C}$. The extract was kept in a room for further usephytochemical analysis was done to identify the plant's constituents and screen for antihyperglycemic activity in albino diabetic rats.

Albino rats (150 - $200 \mathrm{~g}$ body weight) were kept in the animal house, University of Jos, Nigeria. All studies were performed according to the guideline and care and use of laboratory animals adopted by the University of Jos, Jos State, Nigeria. The albino rats were divided into six groups to evaluate the antihyperglycemic property of aqueous extract of the bark of (MYCA) in the treatment of diabetes mellitus.

Diabetes Induced. In vivo antihyperglycemic assay was performed using alloxan and the antihyperglycemic assay to induce diabetes in rats. Alloxan monohydrate was prepared freshly by dissolving one gram in distilled water and kept on ice to avoid degradation while administering to the rats. 
The hyperglycemia activity was induced intraperitoneally using $150 \mathrm{mg} / \mathrm{kg}$ of body weight to overnight fasted albino rats. After three (3) days, the observation of rats with fasting glucose level of $126 \mathrm{mg} / \mathrm{dl}$ or more were considered as diabetic and used for the study. After measuring the initial blood glucose level in all the animals, the blood glucose of the animals was taken in a time interval; $0^{\text {th }}, 2^{\text {nd }}, 4^{\text {th }}$, $6^{\text {th }}, 8^{\text {th }}$, and $24^{\text {th }}$ hours respectively. The rats were fed after the blood glucose level was observed at 24 hours. Antihyperglycemic Assay. The healthy albino rats were divided into five (5) groups with each group containing five (5) members. The albino rats were divided as follow:

- Group I (control group). Rats in this group were served with deionized water

- Group II and Group III (diabetic) received MYCA extract of $500 \mathrm{mg} / \mathrm{kg}$ and $1000 \mathrm{mg} / \mathrm{kg}$.

- Group IV (non- diabetic) use to determine the hypoglycemic effect received $1000 \mathrm{mg} / \mathrm{kg}$ MYCA bark extract dose.

- Group V (diabetic) and Group VI (diabetic) received normal saline and the standard drug, glibenclamide.

The MYCA extract was administered to the albino rats of the respective groups once every day for 21day and their fasting glucose level taken every week to monitor the glucose level of each animal. The rats' blood sample was collected on the on-call stripe, and the glucose level was measured using the on-call glucometer analyzer.
Toxic Effect. The procedure employed was according to the Organization for Economic Cooperation and Development (OECD) guideline for testing of chemicals. The animals (3-male, 3-female) in each group were observed systematically at 1,2 , and 4 hours after the extract was administered daily. The animals were observed for possible changes in the skin, fur, eyes, mucous membrane, and the respiratory, circulatory, autonomic, and central nervous system; somatomotor activity and behavioral changes and mortality. After 24 hours, the numbers of survivors were recorded and were maintained for 14 days with once-daily observation. At the end of the three weeks, all the animals from each group were sacrificed under anesthesia and taken for analysis. Ethical guidelines for the handling and use of animals were strictly followed during the study.

\section{HISTOPATHOLOGY EXAMINATION. After} sacrifice, the internal organs, liver, kidney, heart, lungs, and spleen were dissected and histopathology examination using the method described by [19]. The tissues were carefully removed relative to the treatment (5mg, 50mg, 300mg, and 2000mg) of MYCA extract and placed inside a universal bottle containing bound fluid (fixation) to maintain the original shapes and structures.

The analysis of all data was the Statistical Package for the Social Sciences (SPSS) version 25.

\section{RESULTS AND DISCUSSION}

The result of the phytochemical screening of the ethanolic crude extract of the bark of MYCA is presented in Table 1. Table 1 depicts the alkaloids property of the MYCA bark was absent. Table 1 showed that the ethanolic extracts of Mitragyna ciliata contained some phytochemical groups such as flavonoids, saponins, tannins, Steroids/terpenoids. It also confirmes the presence of Anthraquinones and carbohydrates[20]. The presence of these phytochemical compounds in the ethanolic extracts of MYCA might account for several pharmacological properties of the plant, by previous works of several authors, including antimalarial activity, anti-inflammatory activity, and trypanocidal activity [21-24]. 


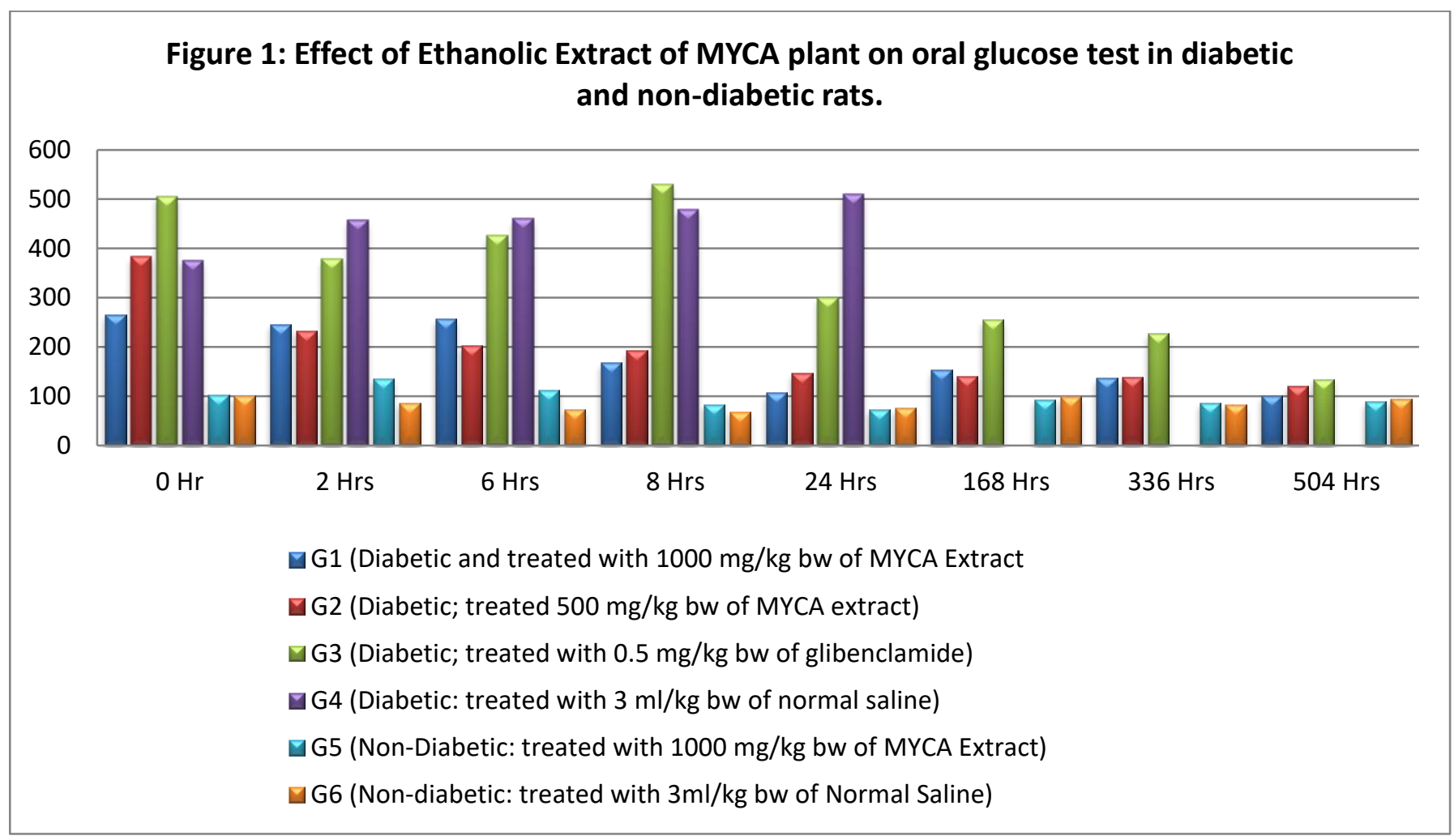

Table: 1: Phytochemical Screening of $M$. iateciliata Bark Extract

\begin{tabular}{ll}
\hline Test & Inference \\
\hline Alkaloids & - \\
Saponins & ++ \\
Terpenoids & + \\
Tannins & +++ \\
Anthraquinones & ++ \\
Cardiac glycoside & ++ \\
Flavonoids & ++
\end{tabular}

Keys: (++) abundant, (+), present, (-) absent
Toxic Effect. The result of the acute toxicity studies is presented in Table 2. None of the animals treated with the crude extract in each group show clinical signs of toxicity, and no mortality was recorded during 24 hours and 14 days of observation. Therefore, the oral $\mathrm{LD}_{50}$ of the extract was taken as to be greater than $2000 \mathrm{mg} / \mathrm{kg}$ for this study. There was no toxicity affect shown among any of the rats.

Antihyperglycemic activity of MYCA. Peak blood glucose level Figure 1 reached between 8 hours to 24 hours after glucose administration, and reduction in blood glucose was observed between 336 hours to 504 hours in extract and glibenclamide treated rats. The effect of the ethanolic extract of the MYCA plant at a dose of $1000 \mathrm{mg} / \mathrm{kg}$ body weight (bw) and $500 \mathrm{mg} / \mathrm{kg}$ bw significantly reduces blood glucose in the 504 hours. At the 168 hours, 336 hours, and 504 hours, diabetic animals in group 4 treated with $3 \mathrm{ml} / \mathrm{kg}$ bw of normal saline died. The result also shows a statistically significant difference $(\mathrm{p}<0.05)$ between the normal rats treated with the extract and the control group, Figure 1. The extract also showed a comparison between the diabetic control rats (alloxan-induced rats not treated) as well as the standard drug (Glibenclamide). The extract showed a time-dependent antihyperglycemic activity with a statistically significant decrease in blood glucose level seen from 6 hours and 24 hours for $1000 \mathrm{mg} / \mathrm{kg}$ bw and $500 \mathrm{mg} / \mathrm{kg}$ bw of the ethanolic extract of MYCA respectively. The figure also showed a decrease in blood glucose level at 2 hours for $500 \mathrm{mg} / \mathrm{kg}$ bw. 


\begin{tabular}{|c|c|c|c|c|c|c|c|}
\hline Table 2: & \multicolumn{7}{|c|}{$\begin{array}{l}\text { Acute Toxicity Test Result Showing the Observed Behavioral Changes of the Rats } \\
(n=5) \text { and Their Various Systems }\end{array}$} \\
\hline Group & Treatment & $\begin{array}{c}\mathrm{Dose} \\
\mathrm{mg} / \mathrm{kg}\end{array}$ & Behavioral & $\begin{array}{l}\text { Respiratory } \\
\text { Activity }\end{array}$ & $\begin{array}{l}\text { Circulatory } \\
\text { Activity }\end{array}$ & $\begin{array}{l}\text { Somatomotor } \\
\text { Activity }\end{array}$ & $\begin{array}{l}\text { CNS/ ANS } \\
\text { Activity }\end{array}$ \\
\hline 1. & Extract & 2000 & - & - & - & - & - \\
\hline 2. & Extract & 300 & - & - & - & - & - \\
\hline 3. & Extract & 50 & - & - & - & - & - \\
\hline 4. & Extract & 5 & - & - & - & - & - \\
\hline 5. & $\begin{array}{l}\text { Distilled } \\
\text { water }\end{array}$ & same & - & - & - & - & - \\
\hline \multicolumn{8}{|c|}{ Key (-) No change in the activities of the rats } \\
\hline
\end{tabular}

The anti-diabetic effects of the ethanolic crude extract of $M Y C A$ and Glibencliamide on alloxan-induced diabetes mellitus were examined in this study. The healthy group has a normal fasting blood glucose level. Therefore, this showed that normal albino rat chow has no effect on the fasting blood glucose level. Diabetic rats treated with MYCA plant bark ethanolic extract significantly $(\mathrm{P}<0.05)$ had lower fasting blood glucose $(\mathrm{FBG})$ levels when compared to the diabetic control group, as shown in Figure 1. It was observed that the MYCA ethanolic crude extract had a more pronounced effect as the time progress as compared to the baseline time. The result in Figure 1 shows a significant $(p<0.05)$ dose. A time-dependent decrease in the blood sugar levels of the treatment group countered to their response to diabetic control values.

The antihyperglycaemic effect was observed at two different levels, for two different doses $(1000 \mathrm{mg} / \mathrm{kg}$ and $500 \mathrm{mg} / \mathrm{kg}$ ), both showed a significant suppression of blood glucose level in glucose fed hyperglycemic albino rats but showed no significantly suppressed glucose level in overnight fasted normoglycemic rats. Such an effect may be accounted for, in part, by a decrease in the rate of intestinal glucose absorption, achieved by an extrapancreatic action inducing stimulation of peripheral glucose utilization or enhancing glycolytic and glycogenic process. It was also observed that the higher dose $(1000 \mathrm{mg} / \mathrm{kg})$ did not show any significant difference in lowering the FBG levels as compared with the lower amount $(500 \mathrm{mg} / \mathrm{kg})$ in diabetic rats.

Literature has shown that the biological activities of flavonoids and alkaloids do include hypoglycemic, hypolipidemia, hypoazotemia, hypotension, among others. The decrease in FBG level may as well be due to the regeneration of beta cells of the presence of antioxidants in the plant, which are known to scavenge the free radicals produced by oxidative damage in the disease state [25-28].

Although the present findings suggest anti-diabetic compound(s) in the ethanoic bark crude extract, the mechanism of this effect requires further studies for clear understanding. The result of the study shows that the three weeks treatment is not enough time for treating diabetes mellitus if ethanolic bark crude extract is administered at both doses used in the study. 
Glibenclamide, however, showed significant $(\mathrm{p}<0.05)$ change in blood glucose levels at 24 hours compared to the normoglycemic rats. Evident drop in FBG levels were noticed from the 24th hours up to the 21st day of treatment. However, the FBG levels of glibenclamide-treated diabatic rats did not appear the same as the values obtained in the healthy control rats. The failure of the drug not reducing the FBG level of diabetic rats could be due to the low potency of the drug.
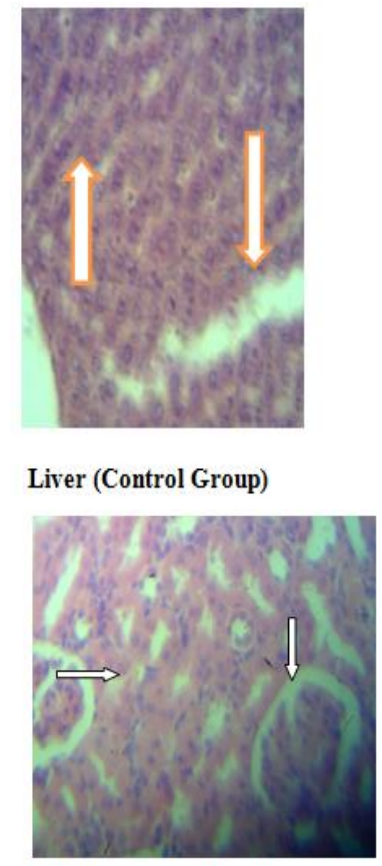

Kidney (Control Group)

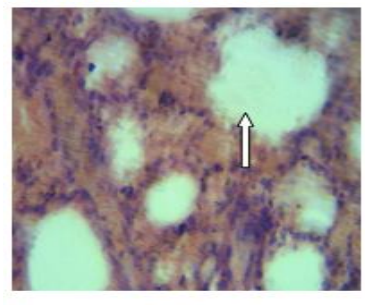

Lung (Control group)

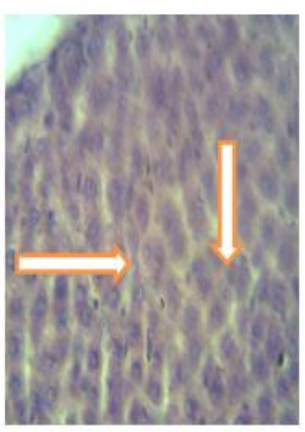

Liver (treatment group)

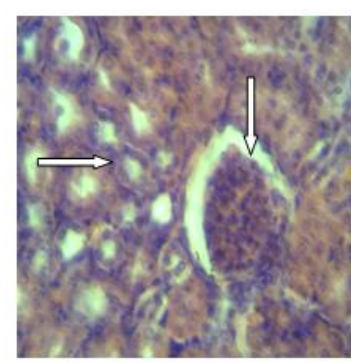

Kidney (Treatment Group)

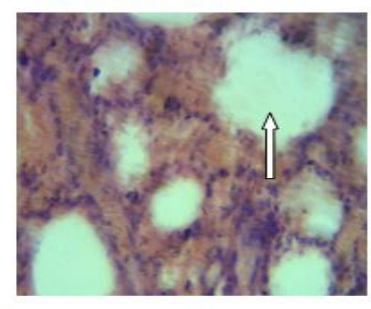

Lung (Treatment Group)

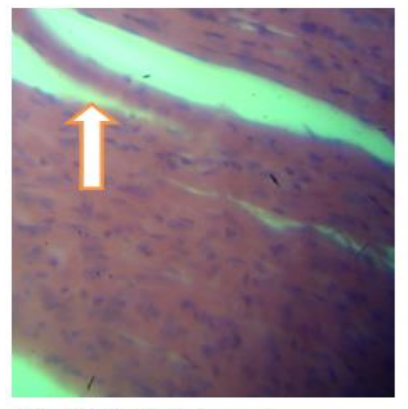

Heart (Control Group)

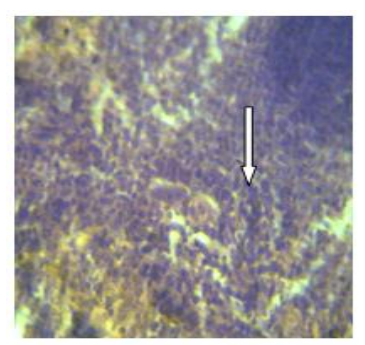

Spleens (Control Group)

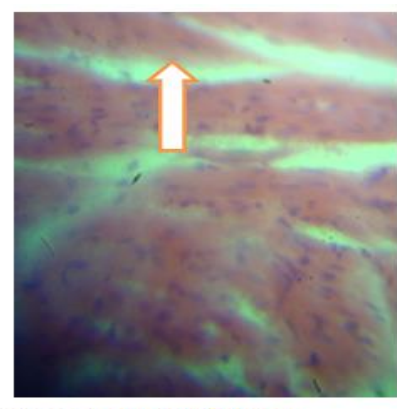

Heart (Treatment Group)

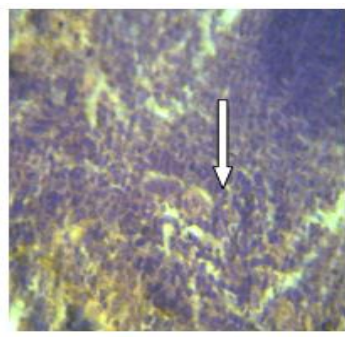

Spleens (Treatment Group)

Figure 2: Cross-sectional of selected organs from the control and treatment groups of the Albino rats. The lethal dose was $2000 \mathrm{mg} / \mathrm{kg}$ bw of MYCA ethanolic extract use to treat the diabetic induced albino rats (treatment group) while distilled water was used for the control groups

Table 3: The effect of ethanolic extract of Mitragyna ciliata on blood parameters in both control and treated rats $(n=5)$

\begin{tabular}{|l|l|l|l|l|l|}
\hline Group & 1 & 2 & 2 & 4 & Control \\
\hline Dose of Extract $\mathrm{mg} / \mathrm{kg}$ & 2000 & 300 & 50 & 5 & Normal saline \\
\hline$(\mathrm{HB}) \mathrm{g} / \mathrm{L}$ & $12.53 \pm 1.94$ & $13.67 \pm 1.03$ & $12.07 \pm 1.17$ & $12.77 \pm 1.16$ & $13.93 \pm 0.55$ \\
\hline$(\mathrm{WBC}) 10^{9} / \mathrm{L}$ & $6.87 \pm 4.20$ & $12.50 \pm 5.80$ & $6.00 \pm 1.82$ & $12.50 \pm 5.80$ & $5.30 \pm 1.40$ \\
\hline$(\mathrm{RBC}) 10^{12} / \mathrm{L}$ & $8.50 \pm 0.10$ & $8.60 \pm 0.50$ & $7.60 \pm 0.07$ & $8.60 \pm 0.60$ & $8.32 \pm 0.01$ \\
\hline $\mathrm{MCV}(\mathrm{fl})$ & $44.00 \pm 0.00$ & $45.00 \pm 0.00$ & $45.00 \pm 0.00$ & $45.00 \pm 0.00$ & $44.00 \pm 0.00$ \\
\hline $\mathrm{MCH}(\mathrm{pg})$ & $15.30 \pm 0.40$ & $15.30 \pm 0.40$ & $16.10 \pm 0.21$ & $15.30 \pm 0.40$ & $15.60 \pm 0.28$ \\
\hline MCHC $(\mathrm{g} / \mathrm{L})$ & $340.00 \pm 0.20$ & $340.00 \pm 8.50$ & $356.00 \pm 0.00$ & $340.00 \pm 8.50$ & $356.00 \pm 4.20$ \\
\hline PDW \% & $36.10 \pm 0.30$ & $40.40 \pm 1.70$ & $38.10 \pm 0.00$ & $40.60 \pm 1.70$ & $36.60 \pm 1.13$ \\
\hline RDW \% & $17.00 \pm 0.10$ & $17.00 \pm 0.50$ & $15.30 \pm 0.20$ & $17.40 \pm 0.60$ & $16.10 \pm 0.14$ \\
\hline
\end{tabular}


PAYE Plenseh Diana et al Int J Sci Res Sci \& Technol. May-June-2021, 8 (3) : 957-965

\begin{tabular}{|l|l|l|l|l|l|} 
PCT & $0.36 \pm 0.30$ & $0.40 \pm 0.40$ & $0.40 \pm 0.01$ & $0.42 \pm 0.40$ & $0.46 \pm 017$ \\
\hline (PLT) $10^{9} / \mathrm{L}$ & $534.00 \pm 5.90$ & $533.00 \pm 35.30$ & $553.00 \pm 35.40$ & $531.50 \pm 42.40$ & $717.00 \pm 267.00$ \\
\hline PCV & $20.00 \pm 0.00$ & $19.33 \pm 1.53$ & $18.00 \pm 6.00$ & $18.00 \pm 2.00$ & $17.00 \pm 1.73$ \\
\hline $\mathrm{N}$ & $75.67 \pm 0.58$ & $77.33 \pm 1.53$ & $77.00 \pm 5.00$ & $80.00 \pm 4.00$ & $82.00 \pm 2.65$ \\
\hline $\mathrm{M}$ & $42.67 \pm 2.13$ & $45.67 \pm 5.69$ & $40.00 \pm 5.00$ & $40.00 \pm 2.00$ & $44.00 \pm 0.00$ \\
\hline $\mathrm{L}$ & $4.33 \pm 0.58$ & $3.33 \pm 3.06$ & $5.00 \pm 1 / 00$ & $2.67 \mathrm{~V} 1.15$ & $1.00 \pm 1.00$ \\
\hline B/E & 0 & 0 & & 0 & 0 \\
\hline
\end{tabular}

The value of $\mathrm{p}>0.05$ (Mean \pm SEM), the result is not statistically significant.

- $\mathrm{WBC}=$ White Blood Cell

- $\mathrm{MCHC}=$ Mean cell Hemoglobin Concentration

- $\mathrm{PDW}=$ Platelet Distribution Width

- $\mathrm{RDW}=$ Red Blood cell Distribution Width

- $\mathrm{MCH}=$ Mean Cell Hemoglobin

- $\mathrm{PCT}=$ Mean Platelet Volume

- $\quad \mathrm{RBC}=$ Red Blood Cell

- $\mathrm{M}=$ Monocytes

- $\mathrm{PLT}=$ Platelet

- $\mathrm{L}=$ Lymphocyte

- $\mathrm{MCV}=$ Mean Corpuscular (erythrocyte) volume

- $\quad \mathrm{B}=$ Basophiles

- $\mathrm{E}=$ Eosinophil

The Hematological Analysis Result of Acute Toxicological Study in Albino Rats

The hematological parameters investigated include the packed cell volume (PCV), platelet count, white blood cell count (WBC), and the white blood cell differential count. This result is presented in Table 3;. However, there were some insignificant variations observed in the hematological indices; these essential parameters were normal and within acceptable ranges in the treated and control groups.

\section{Toxicological effect of albino rats treated with MYCA} extract and control.

The diabetic-induced albino rat treated with the ethanolic extract and the control albino rats were sacrificed and the following organs; liver, heart, lung, spleen, and kidney were dissected for histopathological analysis.

From the analysis, it was revealed an abnormality in the liver of the treatment group that received a single oral dose of $2000 \mathrm{mg} / \mathrm{kg}$ of the extract. No visible abnormalities were observed for the heart, kidney, spleen, and lung. There extract, therefore, shows mild hepatotoxicity at a dose of $2000 \mathrm{mg} / \mathrm{kg}$ of the crude extract.

From Figure 2, the down arrow in the cross-section of the liver (control groups) shows normal nuclei within the hepatocyte, and the up arrow shows a normal radial arrangement within the sinusoid of the normal rat. In the treatment group, the right arrow shows a mild enlargement of the hepatocyte and the down arrow, indicating a slight distortion within the hepatocytes of rats administered with the ethanolic extract. There was no histopathological difference observed between the control and the treatment group at various doses. For the kidney of both the control and treatment groups, no nephrotoxicity effect was observed at all level of the administered dose.

\section{Competing Interest}

All authors declare they have no actual or potential competing financial interest. 


\section{IV.CONCLUSION}

The glucose reduction effects of the various concentration of the ethanolic extract of MYCA suggest that the plant has an ant- diabetic property. The decrease in fasting blood glucose levels in the diabetic rats treated with $M Y C A$ may be due to the lowering of serum glucose levels by enhancing insulin-mediated suppression of hepatic glucose production and enhancing insulin-stimulated glucose uptake by skeletal muscle.

\section{Recommendation}

The further of evaluation of the active ingredient of the MYCA plants using different species of mouse on the suppression of diabetes could be strongly recommended.

\section{REFERENCES}

[1]. Dintsios, C.M., et al., Quantified patient preferences for lifestyle intervention programs for diabetes prevention-a protocol for a systematic review. Syst Rev, 2018. 7(1): p. 214.

[2]. Ratendra, K., et al., Hypoglycemic and hypolipidemic effect of Allopoly herbal formulations in streotozotocin induced diabetes mellitus in arts. International Journal of Diabetes Mellitus, 2011. 3: p. 45-50.

[3]. Elling, D., et al., Sex differences and risk factors for diabetes mellitus - an international study from 193 countries. Global Health, 2018. 14(1): p. 118.

[4]. Kazeem, M.I., J.O. Adamson, and I. Ogunwande, Modes of Inhibition of alpha Amylase and alpha glucosidase by Aqueosu Extract of Morinada Lucide Benth Leaf. Biomedical Research International, 2013: p. 0117.

[5]. WHO, Global Report on Diabetes. 2016, WHO Library: Geneva.
[6]. Kamlesh, P.P., Newer Approaches in the Treatment of Diabetes Millitus. Journal of Medical Sciences, 2013: p. 50-62.

[7]. Badran, M. and I. Laher, Type II Diabetes Mellitus in Arabic Speking Countries. International Journal of Endocrinology, 2012: p. 01-11.

[8]. Kujan, O., et al., The Association between Diabetes Mellitus and Periodontal diseases: A Survey of the Opinions of Dental Professionals. Med Princ Pract, 2018.

[9]. Jack, I.R. and Nwachokon, Ligmas from the Commercial Timber Hallea Ciliatta; Abura. American Journal of Chemistry and Application, 2015: p. 17-20.

[10]. Wikstrom, N., et al., A revised time tree of the asterids: establishing a temporal framework for evolutionary studies of the coffee family (rubiaceae). PLoS One, 2015. 10(5): p. e0126690.

[11]. Meliani, N., et al., Hypoglycaemic effect of Berberis vulgaris L. in normal and streptozotocin-induced diabetic rats. Asian Pacific Journal of Tropical Biomedicine, 2011. 1(6): p. 468-471.

[12]. Abdelmoaty, M.A., et al., Confirmatory studies on the antioxidant and anti-diabetic effect of Quercetin in rats. Indian Journal of Clinical Biochemistry, 2010. 25(2): p. 188-192.

[13]. Hossam, M., et al., Anti-diabetic activity of phenolic compounds from Pecan bark in streptozotocin induced diabetic rats. Journal of Pytochemistry, 2011. 4: p. 337-341.

[14]. Azizi, J., et al., In vitro and in vivo effects of three different Mitragyna speciosa korth leaf extracts on phase II drug metabolizing enzymes--glutathione transferases (GSTs). Molecules, 2010. 15(1): p. 432-41.

[15]. Abraham, A., S. Samuel, and L. Matthew, Pytochemical Analysis of Pathyashadangan kwath and its standardization by HPLC and HPTLC. Journal of Ayurveda and Intergrative Medicine, 2008: p. 01-06. 
[16]. Raja, R.D.A., et al., Antibacterial activity of selected ethnomedicinal plants from SOuth India. Asian Pacific Journal of Tropical Medicine, 2011: p. 375-378.

[17]. Heinrich, M. and S. Gibbons, Ethanopharmacy in drug discovery: an analysis of its role and potential contributions. Journal of Ethanopharmacy, 2001. 53: p. 425-432.

[18]. Bidie, A.D., et al., Influence of Mitragyna ciliata (MYTA) on the microsomal activity of ATPase $\mathrm{Na}+/ \mathrm{K}+$ dependent extract on a rabbit heart. Afr J Tradit Complement Altern Med, 2008. 5(3): p. 294-301.

[19]. Verma, N., et al., Antihyperglycemic activity, antihyperlipedemic activity, heamatological effects and histopathological analysis of Sapindus mukorossi Gaerten fruits in streptozotocin induced diabetic rats. Asian Pacific Journal of Tropical Medicine, 2012: p. 518-522.

[20]. Bidie, A.D.P., et al., evaluation of the toxicity of a methanolic total extract of Mitragyna ciliata a natural anti-malaria. International of Journal of Biological \& Chemical Sciences, 2010: p. 15091518.

[21]. Traore, F., M. Gasquet, and C. Di Gorgio, Antimalarial activity of four plants used in traditional medicine in Mali. Journal of Phytotherapy Researcj, 2007: p. 45-50.

[22]. Adjetey, K.A.T., et al., Preliminary Study of Antimalarial activity of Mitragyna ciliata (Rubiacceae) Aubrev and Pellegr. South African Journal of Botany, 2007: p. 226-229.

[23]. Dongmo, A.B., et al., Anti-inflammatory and analgesic properties of the stem and bark extract on Mitragyna ciliatta (Rubiaceae) Aubrev \& Pellegr. Journal of Enthnopharmacology, 2003. 84(1): p. 17-21.

[24]. Ogbunugafor, H.A., et al., Mitragyna ciliata and its typanocidal activity. African Journal of Biotecnology, 2007. 6(20): p. 2310-2313.
[25]. Borneo, R., et al., Antioxidant capacity of medicinal plants from the Province of Cordoba (Argentina) and their in vitro testing in a model food system. Journal of Food Chemistry, 2009(112): p. 664-670.

[26]. Katalinic, V., et al., screening of 70 medicinal plants extracts for antioxidnat capacity and total phenols. Journal of Food Chemistry, 2006(94): p. 550-557.

[27]. Lee, H.S., Inhibitory activity of cinnamomum casia bark-derived component against rat lens aldose reductase. Journal of Pharmacy and Pharmaceutical Sciences, 2002. 5(3): p. 226-230.

[28]. Lee, S.E., et al., screening of medicinal plan extracts for antioxidant activity. Journal of Life Science, 2003. 73: p. 167-179.

\section{Cite this article as :}

PAYE Plenseh Diana, James McClain, " Antihyperglycemic Activity of The Ethanolic Extract of the Bark of Mitragyna Ciliata (MYCA) in Albino Induced Diabetic Rats", International Journal of Scientific Research in Science and Technology(IJSRST), Print ISSN : 2395-6011, Online ISSN : 2395-602X, Volume 8, Issue 3, pp.957-965, May-June-2021. Available at doi : https://doi.org/10.32628/IJSRST2183133 Journal URL : https://ijsrst.com/IJSRST2183133 